\title{
Pharmacological validation of a novel nonhuman primate measure of thermal responsivity with utility for predicting analgesic effects
}

This article was published in the following Dove Press journal: Journal of Pain Research

\author{
Joshua D Vardigan \\ Andrea K Houghton \\ Henry S Lange \\ Emily D Adarayan \\ Parul S Pall \\ Jeanine E Ballard \\ Darrell A Henze \\ Jason M Uslaner
}

Merck Research Laboratories, West Point, PA, USA
Correspondence: Joshua D Vardigan Merck \& Co., Inc.,

770 Sumneytown Pike, West Point, PA 19486, WP45-121I, USA

Tel +I 2156524052

Email joshua_vardigan@merck.com
Introduction: The development of novel analgesics to treat acute or chronic pain has been a challenge due to a lack of translatable measurements. Preclinical end points with improved translatability are necessary to more accurately inform clinical testing paradigms, which may help guide selection of viable drug candidates.

Methods: In this study, a nonhuman primate biomarker which is sensitive to standard analgesics at clinically relevant plasma concentrations, can differentiate analgesia from sedation and utilizes a protocol very similar to that which can be employed in human clinical studies is described. Specifically, acute heat stimuli were delivered to the volar forearm using a contact heat thermode in the same manner as the clinical setting.

Results: Clinically efficacious exposures of morphine, fentanyl, and tramadol produced robust analgesic effects, whereas doses of diazepam that produce sedation had no effect.

Conclusion: We propose that this assay has predictive utility that can help improve the probability of success for developing novel analgesics.

Keywords: pain, opioid, translatable, monkey, thermode, noxious heat

\section{Introduction}

There is an unmet need for pain relief medicines with improved efficacy and reduced side effects relative to the current standards of care. Recent efforts aimed at developing novel therapeutics that have produced very limited clinical success despite promising effects in preclinical models. ${ }^{1-5}$ One potential reason for the inability to translate preclinical findings to clinical success is a lack of translatable biomarkers. Indeed, the ability to clearly measure target modulation clinically greatly increases the probability of success in the clinic. ${ }^{6,7}$ The challenge is then to identify pharmacodynamic end points that can be directly translated from preclinical species to humans despite a large species gap, particularly since the vast majority of the preclinical measures employed to assess in vivo analgesic potential utilize rodents. ${ }^{8-12}$ Utilizing rodents presents at least four major challenges that might reduce translatability to the clinic: 1) inferring the subjective perception of pain by measuring behavior, 2) utilizing equipment and procedures that are not used in the clinical setting, 3) potential species differences in pain biology relative to human, and 4) potential differences in analgesic compound potency and/or affinity for rodent receptor vs human receptor.

In the studies reported here, we have validated a preclinical pharmacodynamic biomarker to better address the above challenges. Without the ability for a subject to report pain, it is not possible to fully address the first of three aforementioned gaps; 
we have therefore addressed gaps two through four in an effort to identify a biomarker with improved translatability. First, we used nonhuman primates (NHPs) instead of rodents. This is important not only because of potential differences in pain biology between rodents and NHPs but also because of species-specific differences in drug potency or affinity. For example, there are instances when a molecule binds with much greater affinity to the human receptor vs rodent receptor, prohibiting the compound from being characterized in rodents, ${ }^{13,14}$ whereas this issue is seldom if ever noted for NHPs. Second, we used a clinically validated pain assessment tool, the Medoc thermal stimulator, which is an identical instrument to that used clinically. Clinically effective doses of opioids and alpha-2 adrenergic agonists demonstrate clear analgesic efficacy in healthy human subjects receiving acute noxious stimuli delivered by this thermode device. ${ }^{15-19} \mathrm{We}$ hypothesized that acute thermal stimulation in healthy NHPs might represent an end point sensitive to drug targets with therapeutic potential and at the very least would translate to healthy human assessment of target modulation in Phase I testing.

\section{Methods}

\section{Subjects}

Eight single- or pair-housed male and female rhesus macaques weighing 4-12 kg were used in the experiments (three males and five females). Personality profiles were not created. Subjects were maintained on a 12-h light cycle (06:30-18:30 h) with room temperatures maintained at $22 \pm 2^{\circ} \mathrm{C}$. Testing was performed within a separate colony room, to which each animal was habituated for 15-30 min before testing, which took place between 10:00 and 14:30 h. Subjects were fed their full daily regimen of food (Purina High Protein Monkey Diet no. 5045) at 08:00 h, and water was available ad libitum. All monkeys were given various fresh fruits and vegetables daily in addition to the standard food regimen. Principles from the Guide for the Care and Use of Laboratory Animals, the National Institutes of Health, and the United States Department of Agriculture were followed, and all protocols were approved by the Merck \& Co., Inc. (West Point, PA, USA) and the Institutional Animal Care and Use Committee.

\section{Drugs}

Morphine, fentanyl, and tramadol were selected as clinically active positive controls and were purchased from SigmaAldrich Co., St Louis, MO, USA, dissolved in saline and administered subcutaneously (SC) at $0.2 \mathrm{~mL} / \mathrm{kg} 30 \mathrm{~min}$ prior to testing. Doses were calculated as a function of base to account for salt factors. The benzodiazepine diazepam (DZP) was selected as a negative control to assess whether a sedative compound without clinical analgesic properties would inhibit responding to thermode stimuli. The dose and route of DZP that produced modest sedation in rhesus macaque were selected, ${ }^{20-22}$ and it was obtained in solution form from Hospira (San Clemente, CA, USA) and administered $\mathrm{SC}$ at $0.4 \mathrm{~mL} / \mathrm{kg}$. Doses for positive controls were selected to produce exposures matching those reported as active in postoperative pain. ${ }^{23-25}$ Specifically, NHP exposures were intended to match the clinical minimum efficacious concentration (MEC) defined as the trough plasma level measured just prior to patient-controlled administration of another dose of analgesics.

\section{Thermode behavioral testing}

Animals were chaired with their arms restrained against the front horizontal panel using an umbilical tape. Veterinary wrap was applied to each wrist to prevent abrasive contact with the tape, which was then tied around the wrists and affixed to a lower front portion of the chair with sufficient slack to avoid distress and allow for visible withdrawal motions. Each animal's hair on the underside of its forearms was shaved, and the thermode stimulator was attached to the shaved area of the left or right forearm using veterinary wrap. Thermal stimulation was delivered via Medoc Thermode software and triggered with an external handheld trigger. Four heat stimuli $\left(44^{\circ} \mathrm{C}, 46^{\circ} \mathrm{C}, 48^{\circ} \mathrm{C}\right.$, or $\left.50^{\circ} \mathrm{C}\right)$ were presented pseudorandomly in six blocks (Table 1). These temperatures were selected based on reported human pain thresholds with the same thermode device. ${ }^{15,19,26,27}$ Each stimulus was presented for $5 \mathrm{~s}$, and stimuli were presented under a variable interval of $22.5 \mathrm{~s}$ (range $=15-30 \mathrm{~s}$ ). Each response was assessed using a 3 -point scale, where $0=$ no response, $1=$ response consisting of a single clear arm movement, and $2=$ multiple arm or body movements. Occasionally, a score of 0.5 was used to indicate a very small or questionable response. All experiments were performed within subjects; thus, each animal

Table I Stimulus intensity $\left({ }^{\circ} \mathrm{C}\right)$ in each block of four stimuli, in sequential order from top to bottom

\begin{tabular}{llllll}
\hline Block & & & & & \\
\hline I & $\mathbf{2}$ & $\mathbf{3}$ & $\mathbf{4}$ & $\mathbf{5}$ & $\mathbf{6}$ \\
\hline 46 & 50 & 44 & 48 & 48 & 46 \\
50 & 48 & 46 & 50 & 44 & 50 \\
44 & 46 & 48 & 44 & 50 & 44 \\
48 & 44 & 50 & 46 & 46 & 48 \\
\hline
\end{tabular}


received all treatments in pseudorandom order. Testing was performed twice per week, and the experimenter was blind to drug treatments. At least half of the animals initially selected for testing did not exhibit adequate behavioral responses to thermode stimulation and were therefore not selected for testing. Only animals exhibiting a minimum mean score of 0.5 at $48^{\circ} \mathrm{C}$ and of 1.0 at $50^{\circ} \mathrm{C}$ under repeated baseline conditions were selected for study. A sample of subjects from the first behavioral screening is shown in Figure 1, though it does not represent all animals ultimately included in drug studies.

\section{Pharmacokinetics}

Concentrations were quantified using a Transcend LX2 Multiplexed UPLC system coupled with a SCIEX (API4500 for morphine and API6500 for fentanyl and tramadol) triple quadruple mass spectrometer (Thermo Fisher Scientific, Waltham, MA, USA). The study samples and triplicate standard curves spiked in control matrix ( $30 \mu \mathrm{L}$ of $2 \%$ formic acid per $100 \mu \mathrm{L}$ of monkey plasma) were prepared for analysis using a protein precipitation extraction method. The chromatographic separation was performed using an Acquity UPLC HSS T3 $(50 \times 2.1 \times 1.8 \mu \mathrm{m})$ column. The flow rate was $0.750 \mathrm{~mL} / \mathrm{min}$, and the liquid chromatography (LC) gradient method was started with $80 \%$ water with $0.1 \%$ formic acid and ramped to $98 \%$ acetonitrile with $0.1 \%$ formic acid for morphine, $100 \%$ water with $0.1 \%$ formic acid and ramped to $98 \%$ acetonitrile with $0.1 \%$ formic acid for fentanyl, and $95 \%$ water with $0.1 \%$ formic acid and ramped to $98 \%$ acetonitrile with $0.1 \%$ formic acid for tramadol. The concentration of L-005346293-001D005 in the samples was determined using MultiQuant 3.0.1 based on triplicate standard curves ranging from 5 to $10,000 \mathrm{nM}$ for morphine, from 0.1 to $1,000 \mathrm{nM}$ for fentanyl, and from 2 to $10,000 \mathrm{nM}$ for tramadol.

\section{Statistics}

Two-factor (temperature [temp] and group) repeated measures analyses of variance (ANOVAs) were performed to test for the main effects of temperature and group, as well as interactions between these factors. At temperatures where significant treatment effects were observed,
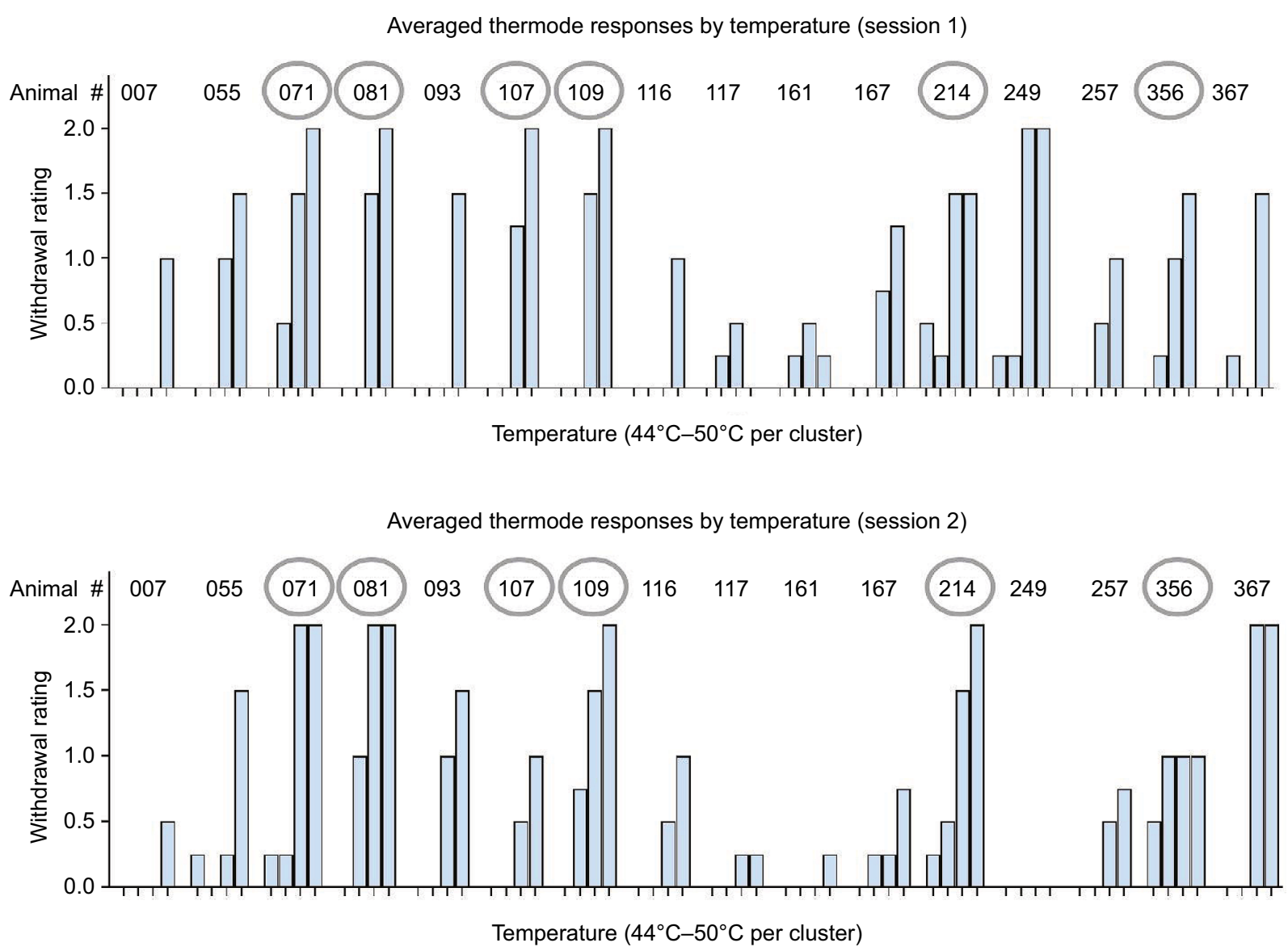

Figure I Baseline response of subject candidates over two sessions.

Note: Only six animals met criteria from the initial cohort of 16 tested (circled). 
paired samples $t$-tests were used to test for the effects of individual treatment conditions. To control multiplicity, individual treatments were compared to control only at temperatures where significant treatment effects ( $F$-test) were observed. This comparison consisted of paired $t$-tests of each active treatment vs the zero (vehicle) dose. To further control for multiplicity, a "step-down" approach was then used for $t$-tests, whereby the highest dose was tested first (vs vehicle), and the next dose was only tested if the highest dose was significant (and so on until the $t$-test was nonsignificant).

\section{Results}

Thermode stimulation resulted in a temperature-dependent increase in the withdrawal response. At $44^{\circ} \mathrm{C}$ no appreciable response was observed, whereas at $46^{\circ} \mathrm{C}-50^{\circ} \mathrm{C}$, temperature-dependent responses were produced. In the morphine dose-response (Figure 2), a two-factor (temp $\times$ group) repeated measures ANOVA indicated significant main effects of temp $\left(F_{3,90}=91.1, p<0.001\right)$ and group $\left(F_{3,90}=\right.$ 48.4, $p<0.001)$ and a significant interaction of temp and group $\left(F_{9,90}=8.1, p<0.001\right)$. Repeated measures ANOVA at each temperature revealed a significant effect of group at $46^{\circ} \mathrm{C}\left(F_{3,18}=4.6, p<0.05\right), 48^{\circ} \mathrm{C}\left(F_{3,18}=26.3, p<0.001\right)$, and $50^{\circ} \mathrm{C}\left(F_{3,18}=24.9, p<0.001\right)$, but not $44^{\circ} \mathrm{C}\left(F_{3,18}=3.0\right.$, $p=0.056)$. At temperatures where significant group effects were observed, morphine produced a significant reduction in responding at both $1 \mathrm{mg} / \mathrm{kg}(p<0.05, p<0.01$, and $p<0.01$ at $46-50^{\circ} \mathrm{C}$, respectively) and $3 \mathrm{mg} / \mathrm{kg}(p<0.01$ at all temps; paired samples $t$-test, $\mathrm{N}=7$ ). In contrast, the $\mathrm{GABA}_{\mathrm{A}}$ receptor-positive allosteric modulator DZP $(2 \mathrm{mg} / \mathrm{kg}) \mathrm{had}$

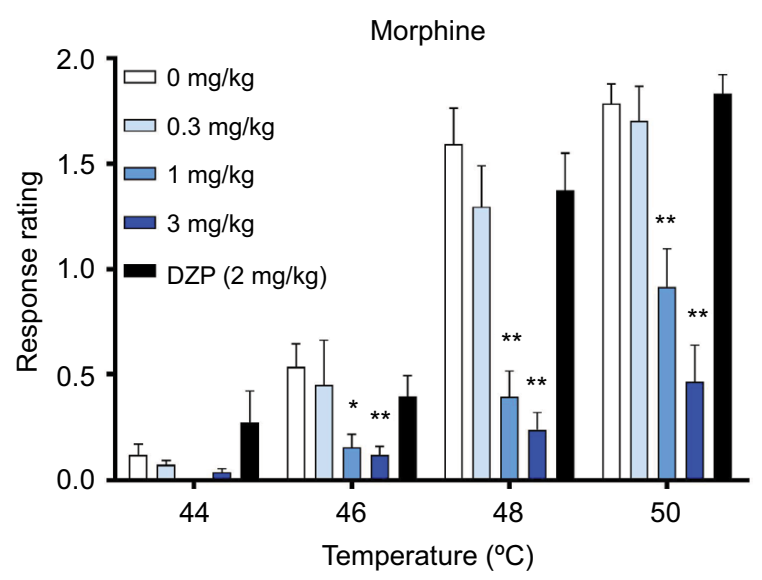

Figure 2 Baseline response to heat stimulation $(0 \mathrm{mg} / \mathrm{kg}$, white bars) and effect of morphine and DZP on heat-induced responses.

Note: ${ }^{*} p<0.05$, ${ }^{* *} p<0.01$, paired samples $t$-test $(N=7$, mean $\pm S E M)$.

Abbreviations: DZP, diazepam; SEM, standard error of the mean. no effect on responding despite producing visible sedation. Total plasma exposures resulting from the doses of morphine tested are shown in Table 2.

A two-factor (temp $\times$ group) repeated measures ANOVA also indicated significant main effects of temp $\left(F_{3,77}=\right.$ $210.4, p<0.001)$ and group $\left(F_{2,77}=44.6, p<0.001\right)$ and a significant interaction of temp and group $\left(F_{6,77}=6.4, p<\right.$ 0.001 ) in the fentanyl dose-response (Figure 3, total plasma exposures in Table 3). Repeated measures ANOVA at each temperature revealed a significant effect of group at $46^{\circ} \mathrm{C}$ $\left(F_{2,14}=13.3, p<0.001\right), 48^{\circ} \mathrm{C}\left(F_{2,14}=24.8, p<0.001\right)$ and $50^{\circ} \mathrm{C}\left(F_{2,14}=12.3, p<0.001\right)$, but not $44^{\circ} \mathrm{C}\left(F_{2,14}=1.9\right.$, $p=0.18)$. At temperatures where significant group effects were observed, fentanyl produced a significant reduction in responding at both $0.005 \mathrm{mg} / \mathrm{kg}\left(p<0.05\right.$ at $46^{\circ} \mathrm{C}$ and

Table 2 Plasma concentration of morphine $0.5 \mathrm{~h}$ after administration ${ }^{\mathrm{a}}$

\begin{tabular}{ll}
\hline Dose $(\mathrm{mg} / \mathrm{kg})$ & Total plasma $(\mu \mathrm{M})$ \\
\hline 0.3 & $0.51 \pm 0.12$ \\
1.0 & $1.41 \pm 0.59$ \\
3.0 & $4.22 \pm 0.72$ \\
\hline
\end{tabular}

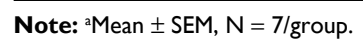

Abbreviation: SEM, standard error of the mean.

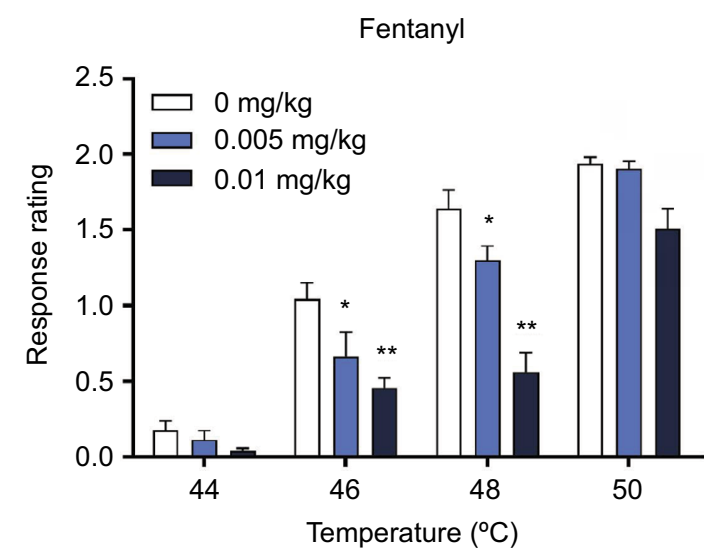

Figure 3 Effect of fentanyl on heat-induced responses.

Note: ${ }^{*} p<0.05$, ${ }^{*} p<<0.00$ I, paired samples $t$-test $(\mathrm{N}=8$, mean $\pm \mathrm{SEM})$.

Abbreviation: SEM, standard error of the mean.

Table 3 Plasma concentration of fentanyl I.5 h after administration ${ }^{\mathrm{a}}$

\begin{tabular}{ll}
\hline Dose $(\mathrm{mg} / \mathrm{kg})$ & Total plasma $(\mu \mathrm{M})$ \\
\hline 0.005 & $0.0014 \pm 0.000$ \\
0.010 & $0.0031 \pm 0.001$ \\
\hline
\end{tabular}

Note: a Mean \pm SEM, $N=8$ per group.

Abbreviation: SEM, standard error of the mean. 
$\left.48^{\circ} \mathrm{C}\right)$ and $0.01 \mathrm{mg} / \mathrm{kg}\left(p<0.001\right.$ at $46^{\circ} \mathrm{C}$ and $48^{\circ} \mathrm{C}$; paired samples $t$-test, $\mathrm{N}=8$ ).

In the tramadol dose-response (Figure 4, total plasma exposures in Table 4), a two-factor (temp $\times$ group) repeated measures ANOVA indicated significant main effects of temp $\left(F_{3,77}=257.1, p<0.001\right)$ and group $\left(F_{2,77}=20.8, p<0.001\right)$ and a significant interaction of temp and group $\left(F_{6,77}=2.5\right.$, $p<0.05)$. Repeated measures ANOVA at each temperature

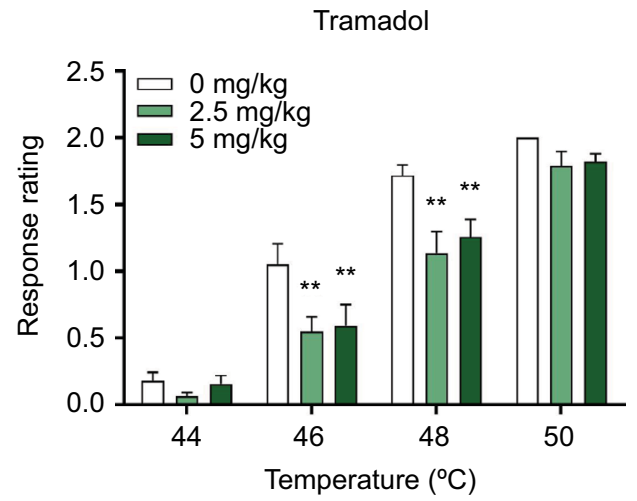

Figure 4 Effect of tramadol on heat-induced responses. Note: ${ }^{* *} p<0.0$ I, paired samples $t$-test $(N=8$, mean \pm SEM).

Abbreviation: SEM, standard error of the mean.

Table 4 Plasma concentration of tramadol I h after administration ${ }^{\mathrm{a}}$

Dose (mg/kg)

\begin{tabular}{ll}
\hline 2.5 & $2.11 \pm 0.94$ \\
5.0 & $4.16 \pm 1.29$
\end{tabular}

Note: a Mean \pm SEM, $\mathrm{N}=8$ per group.

Abbreviation: SEM, standard error of the mean. revealed a significant effect of group at $46^{\circ} \mathrm{C}\left(F_{2,14}=23.6\right.$, $p<0.001)$ and $48^{\circ} \mathrm{C}\left(F_{2,14}=8.4, p<0.01\right)$ but not $44^{\circ} \mathrm{C}$ $\left(F_{2,14}=1.8, p=0.20\right)$ or $50^{\circ} \mathrm{C}\left(F_{2,14}=3.7, p=0.05\right)$. At temperatures where significant group effects were observed, tramadol produced a significant reduction in responding at both $2.5 \mathrm{mg} / \mathrm{kg}\left(p<0.001\right.$ and $p<0.01$ at $46^{\circ} \mathrm{C}$ and $48^{\circ} \mathrm{C}$, respectively) and $5 \mathrm{mg} / \mathrm{kg}\left(p<0.01\right.$ and at $46^{\circ} \mathrm{C}$ and $48^{\circ} \mathrm{C}$; paired samples $t$-test, $\mathrm{N}=8$ ).

\section{Discussion}

We present the first report showing heat-induced arm-withdrawal behavior in NHP using a Medoc CHEPS protocol similar to that employed in clinical pain testing, and we have attempted to validate the paradigm with clinically relevant exposures of analgesics. In all cases, these analgesics were effective. In contrast, the $\mathrm{GABA}_{\mathrm{A}}$ receptor-positive allosteric modulator DZP (2 mg/kg, selected as a negative control to test whether reductions in arm withdrawal were related to sedation) had no effect on the response despite producing observable sedation. Thus, despite using a behavioral end point in place of clinical subject reports, we believe this assay presents an improvement in translation relative to other preclinical assays available.

The doses of each positive control tested were selected based on their ability to produce clinically relevant plasma exposures (Tables 2-4). However, in order to more systematically determine whether the concentration-effect functions for the NHP thermode test are predictive of effects in the clinic, the MEC of each compound was compared clinically

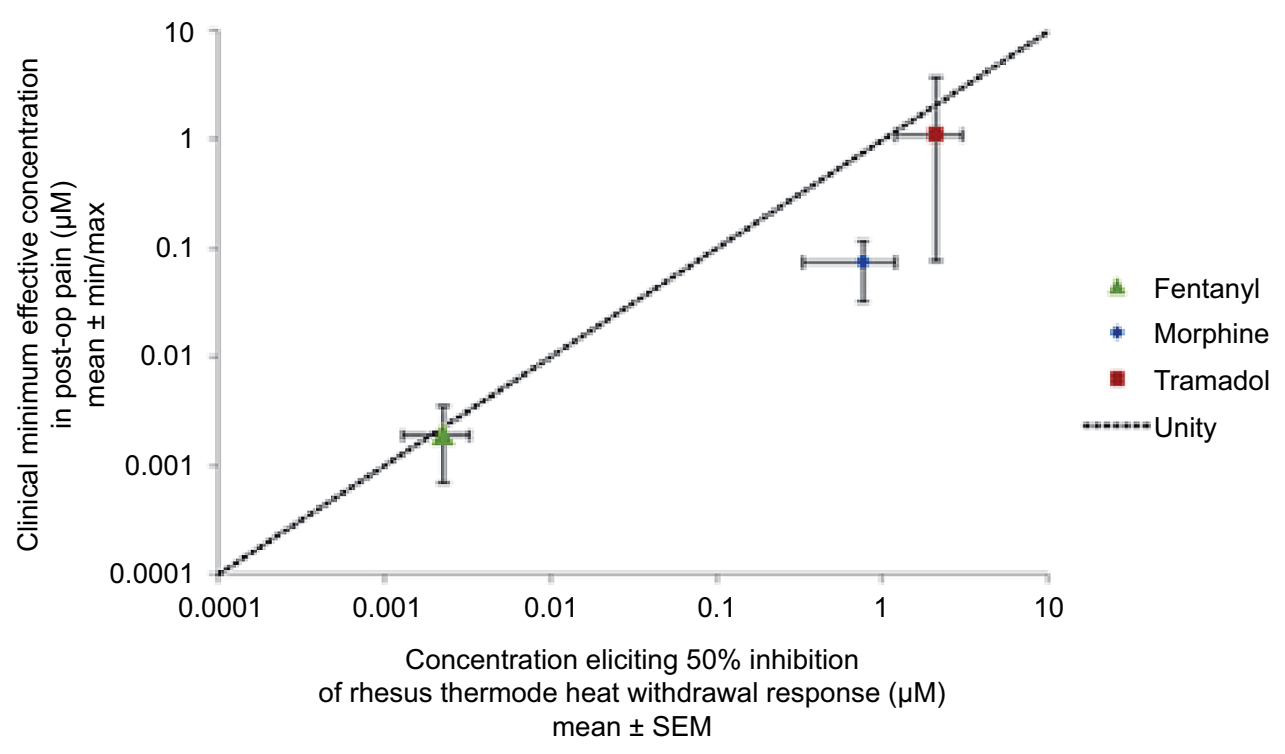

Figure 5 Human post-op MEC vs rhesus $I C_{50}$ at $46^{\circ} \mathrm{C}$.

Abbreviations: max, maximum; MEC, minimum efficacious concentration; min, minimum; post-op, post-operative; SEM, standard error of the mean. 
with its $\mathrm{IC}_{50}$ in the NHP test at $46^{\circ} \mathrm{C}$ (Figure 5). The clinically efficacious opioids morphine, fentanyl, and tramadol were active at doses matching their clinical MEC, ${ }^{23,24}$ and we therefore believe that their activity in the present thermode paradigm aligns well with clinical target modulation. Some of these doses are also known to be active in other NHP pain models with less translatable methodology. ${ }^{28-30}$ Interestingly, clinical populations afflicted with chronic pain report a hypersensitivity to thermode-evoked pain scores, ranging from allodynia to hyperalgesia. ${ }^{27}$ It is therefore possible that inducing thermode hypersensitivity in NHPs could further increase the assay's similarity to these patient populations for future preclinical studies. Topical capsaicin application may represent one practical avenue for inducing hypersensitivity to thermode stimuli, as it is already used in clinical thermode paradigms. ${ }^{31,32}$

Of note, more than half of the subjects in the initial screening cohort did not exhibit robust and/or reproducible responses to thermode stimulation and were not selected for drug testing. The reason for this observation cannot be objectively determined from the present data, but is likely the result of the limited temperatures employed. For human safety, the clinical device used in these experiments has a restricted temperature range at which stimuli can be maintained (if the stimuli are intended to last for a second or more), peaking around $50^{\circ} \mathrm{C}$. As humans are shown to rate $50^{\circ} \mathrm{C}$ anywhere from $20 \%$ to $75 \%$ of "maximal pain", $15,19,26,27$ it is expected that NHPs would express a range of responses between subjects and that many of these responses would not be overtly observable. Indeed, much of the reported NHP experiments employing noxious heat use higher, potentially tissue-damaging temperatures ${ }^{28,33}$ in order to evoke a robust response. However, the stimuli used herein are very typical of clinical experiments, and opioid analgesics are known to markedly affect human pain reporting at this range irrespective of whether individuals rate these temperatures as moderate or extreme. ${ }^{15,19}$ As a species, male NHPs have also likely evolved to be somewhat less expressive of pain behaviors than females, as they are known to compete for colony dominance and be potential targets for aggression. ${ }^{34}$ The present study found less males meeting selection criteria than females, which may be consistent with this notion. Whatever the case, the goal of the present study was to generate a group of animals that showed a reproducible response against which analgesics could be tested, and therefore, the selection of animals that responding to these temperatures was necessary. Furthermore, the drug sensitivity in these animals appears to align well with human (at least for the compounds tested), which helps mitigate concerns about whether the subjects employed here are unique and not predictive of effects in humans.

It is also worth noting that any mechanism intended for translation from NHP to human dose should be characterized with regard to its active metabolites, as the potential exists for species differences in metabolite clearance. In the present study, the active morphine exposures appear somewhat less similar to the clinical MEC relative to fentanyl and tramadol, and this could potentially be explained by species differences in metabolism of morphine-6-glucuronide, a metabolite known to be active in human..$^{19}$ Indeed, this slight discrepancy between active human and rhesus exposure seems to be consistent with other morphine dose-responses observed in NHP. ${ }^{28-30}$ In any case, active doses of opioids in this assay especially fentanyl and tramadol - align extremely well with the clinic, and the methods presented here may present an improvement in translational methodology.

\section{Acknowledgment}

No funding agencies were used to support this research. All authors are currently employed at Merck \& Co., Inc.

\section{Disclosure}

The authors report no conflicts of interest in this work.

\section{References}

1. Huggins JP, Smart TS, Langman S, Taylor L, Young T. An efficient randomised, placebo-controlled clinical trial with the irreversible fatty acid amide hydrolase-1 inhibitor PF-04457845, which modulates endocannabinoids but fails to induce effective analgesia in patients with pain due to osteoarthritis of the knee. Pain. 2012;153(9):1837-1846.

2. Kalliomaki J, Annas P, Huizar K, et al. Evaluation of the analgesic efficacy and psychoactive effects of AZD1940, a novel peripherally acting cannabinoid agonist, in human capsaicin-induced pain and hyperalgesia. Clin Exp Pharmacol Physiol. 2013;40(3):212-218.

3. Ostenfeld T, Price J, Albanese M, et al. A randomized, controlled study to investigate the analgesic efficacy of single doses of the cannabinoid receptor-2 agonist GW842166, ibuprofen or placebo in patients with acute pain following third molar tooth extraction. Clin J Pain. 2011;27(8):668-676.

4. Pereira A, Chappell A, Dethy J, et al. A proof-of-concept (POC) study including experimental pain models (EPMs) to assess the effects of a CB2 agonist (LY2828360) in the treatment of patients with osteoarthritic (OA) knee pain. Clin Pharmacol Ther. 2013;93(S1):S56-S57.

5. Mogil JS. Laboratory environmental factors and pain behavior: the relevance of unknown unknowns to reproducibility and translation. Lab Anim (NY). 2017;46(4):136-141.

6. Sultana SR, Roblin D, O'Connell D. Translational research in the pharmaceutical industry: from theory to reality. Drug Discov Today. 2007;12(9-10):419-425.

7. Finley Austin MJ, Babiss L. Commentary: where and how could biomarkers be used in 2016? AAPS J. 2006;8(1):E185-E189.

8. Schouenborg J, Kalliomaki J. Functional organization of the nociceptive withdrawal reflexes. I. Activation of hindlimb muscles in the rat. Exp Brain Res. 1990;83(1):67-78. 
9. Schouenborg J, Holmberg H, Weng HR. Functional organization of the nociceptive withdrawal reflexes. II. Changes of excitability and receptive fields after spinalization in the rat. Exp Brain Res. 1992;90(3):469-478.

10. Han JS, Bird GC, Li W, Jones J, Neugebauer V. Computerized analysis of audible and ultrasonic vocalizations of rats as a standardized measure of pain-related behavior. J Neurosci Methods. 2005;141(2):261-269.

11. Jourdan D, Ardid D, Chapuy E, Eschalier A, Le Bars D. Audible and ultrasonic vocalization elicited by single electrical nociceptive stimuli to the tail in the rat. Pain. 1995;63(2):237-249.

12. Levine JD, Feldmesser M, Tecott L, Gordon NC, Izdebski K. Paininduced vocalization in the rat and its modification by pharmacological agents. Brain Res. 1984;296(1):121-127.

13. Ase AR, Honson NS, Zaghdane H, Pfeifer TA, Seguela P. Identification and characterization of a selective allosteric antagonist of human $\mathrm{P} 2 \times 4$ receptor channels. Mol Pharmacol. 2015;87(4):606-616.

14. Cialdai C, Tramontana M, Patacchini R, et al. MEN15596, a novel nonpeptide tachykinin NK2 receptor antagonist. Eur J Pharmacol. 2006;549(1-3):140-148.

15. Cortinez LI, Hsu YW, Sum-Ping ST, et al. Dexmedetomidine pharmacodynamics: part II: crossover comparison of the analgesic effect of dexmedetomidine and remifentanil in healthy volunteers. Anesthesiology. 2004;101(5):1077-1083.

16. Niesters M, Aarts L, Sarton E, Dahan A. Influence of ketamine and morphine on descending pain modulation in chronic pain patients: a randomized placebo-controlled cross-over proof-of-concept study. $\mathrm{Br}$ J Anaesth. 2013;110(6):1010-1016.

17. Eisenberg E, Midbari A, Haddad M, Pud D. Predicting the analgesic effect to oxycodone by "static" and "dynamic" quantitative sensory testing in healthy subjects. Pain. 2010;151(1):104-109.

18. Edwards RR, Haythornthwaite JA, Tella P, Max MB, Raja S. Basal heat pain thresholds predict opioid analgesia in patients with postherpetic neuralgia. Anesthesiology. 2006;104(6):1243-1248.

19. Murthy BR, Pollack GM, Brouwer KL. Contribution of morphine6-glucuronide to antinociception following intravenous administration of morphine to healthy volunteers. J Clin Pharmacol. 2002;42(5): 569-576.

20. Tannenbaum PL, Tye SJ, Stevens J, et al. Inhibition of orexin signaling promotes sleep yet preserves salient arousability in monkeys. Sleep. 2016;39(3):603-612

21. Tannenbaum PL, Stevens J, Binns J, et al. Orexin receptor antagonistinduced sleep does not impair the ability to wake in response to emotionally salient acoustic stimuli in dogs. Front Behav Neurosci. 2014;8:182.
22. Uslaner JM, Tye SJ, Eddins DM, et al. Orexin receptor antagonists differ from standard sleep drugs by promoting sleep at doses that do not disrupt cognition. Sci Transl Med. 2013;5(179):179ra44.

23. Dahlstrom B, Tamsen A, Paalzow L, Hartvig P. Patient-controlled analgesic therapy, part IV: pharmacokinetics and analgesic plasma concentrations of morphine. Clin Pharmacokinet. 1982;7(3): 266-279.

24. Gourlay GK, Kowalski SR, Plummer JL, Cousins MJ, Armstrong PJ. Fentanyl blood concentration-analgesic response relationship in the treatment of postoperative pain. Anesth Analg. 1988;67(4):329-337.

25. Lehmann KA, Kratzenberg U, Schroeder-Bark B, Horrichs-Haermeyer G. Postoperative patient-controlled analgesia with tramadol: analgesic efficacy and minimum effective concentrations. Clin J Pain. 1990;6(3):212-220.

26. Eisenach JC, Hood DD, Curry R. Relative potency of epidural to intrathecal clonidine differs between acute thermal pain and capsaicininduced allodynia. Pain. 2000;84(1):57-64.

27. Vierck CJ, Wong F, King CD, Mauderli AP, Schmidt S, Riley JL 3rd. Characteristics of sensitization associated with chronic pain conditions. Clin J Pain. 2014;30(2):119-128.

28. Maguire DR, France CP. Impact of efficacy at the mu-opioid receptor on antinociceptive effects of combinations of mu-opioid receptor agonists and cannabinoid receptor agonists. J Pharmacol Exp Ther. 2014;351(2):383-389.

29. Butelman ER, Ball JW, Harris TJ, Kreek MJ. Topical capsaicin-induced allodynia in unanesthetized primates: pharmacological modulation. $J$ Pharmacol Exp Ther. 2003;306(3):1106-1114.

30. Dykstra LA, Gmerek DE, Winger G, Woods JH. Kappa opioids in rhesus monkeys. I. Diuresis, sedation, analgesia and discriminative stimulus effects. J Pharmacol Exp Ther. 1987;242(2):413-420.

31. Liu M, Max MB, Robinovitz E, Gracely RH, Bennett GJ. The human capsaicin model of allodynia and hyperalgesia: sources of variability and methods for reduction. J Pain Symptom Manage. 1998;16(1):10-20.

32. Arendt-Nielsen L, Andersen OK, Jensen TS. Brief, prolonged and repeated stimuli applied to hyperalgesic skin areas: a psychophysical study. Brain Res. 1996;712(1):165-167.

33. Dykstra LA, Woods JH. A tail withdrawal procedure for assessing analgesic activity in rhesus monkeys. J Pharmacol Methods. 1986;15(3):263-269.

34. Wooddell LJ, Kaburu SS, Suomi SJ, Dettmer AM. Elo-rating for tracking rank fluctuations after demographic changes involving semi-freeranging rhesus macaques (Macaca mulatta). JAm Assoc Lab Anim Sci. 2017;56(3):260-268.

\section{Journal of Pain Research}

\section{Publish your work in this journal}

The Journal of Pain Research is an international, peer reviewed, open access, online journal that welcomes laboratory and clinical findings in the fields of pain research and the prevention and management of pain. Original research, reviews, symposium reports, hypothesis formation and commentaries are all considered for publication.

\section{Dovepress}

The manuscript management system is completely online and includes a very quick and fair peer-review system, which is all easy to use. Visit http://www.dovepress.com/testimonials.php to read real quotes from published authors. 